\title{
A JUDICIALIZAÇÃO DO DIREITO À EDUCAÇÃO INFANTIL NO MUNICÍPIO DE SÃO PAULO
}

Daniela Marques da Silva ${ }^{1}$

\begin{abstract}
Resumo
A educação, segundo TRINDADE (2007), é vital para romper com a histórica dependência científica, tecnológica e cultural de nosso País e consolidar um projeto de nação democrática, autônoma, soberana e solidária, propiciando dessa maneira um crescimento do corpo social em direção a um Estado Democrático de Direito que efetive o atendimento aos Direitos Fundamentais e Sociais. O direito à educação, como direito público subjetivo, é um direito social fundamental. Os artigos $6^{\circ} \mathrm{e}$ 205 da Constituição Federal, com três objetivos definidos, estão diretamente relacionados com os fundamentos do Estado brasileiro: a) pleno desenvolvimento da pessoa; b) preparo para o exercício da cidadania; e c) qualificação para o trabalho. O objetivo geral deste trabalho foi verificar o direito à educação infantil em São Paulo - SP e analisar a quantidade de vagas, a demanda e o processo de judicialização. Nesse sentido, por meio dos dados de relatório da Ouvidoria-Geral do Município e da Defensoria Pública do Estado de São Paulo, buscou-se compreender como se organizam e atuam no enfrentamento a possíveis violações de direitos à educação infantil no município de São Paulo. Pelo Poder Executivo Municipal, a educação é prioridade posto que consta nas metas de gestão a serem atingidas, contudo as incursões do Ministério Público com apoio em ações da Defensoria Pública demonstram a configuração de uma meta própria, sob ótica das suas respectivas instituições. Assim, esse encontro de interesses diversos muitas vezes recorre à Ouvidoria-Geral do Município para um equilíbrio, ou como espaço público que mitiga conflitos, inclusive de natureza abrangente como a política pública da educação infantil. O objetivo específico do presente trabalho é demonstrar a contribuição decisiva da Ouvidoria-Geral nas discussões de políticas públicas. As informações sobre os processos ligados à infância e juventude são de praxe classificados como segredo de justiça, o que impede a realização de pesquisas mais aprofundadas sobre o tema. Dessa forma, é relevante que se discuta o acesso a esse tipo de informação pela sociedade ou, no mínimo, pela Academia, mediante termo de compromisso de utilizar os dados para fins de pesquisa científica.
\end{abstract}

Palavras-chave: Educação infantil. Vagas. Judicialização.

\section{DOI:10.37814/2594-5068.2020v3.p191-202}

1 Diretora de Divisão Técnica no Atendimento ao Público e Interlocução Social da Ouvidoria-Geral do Município de São Paulo. Bacharel em Direito pelas Faculdades Integradas Rio Branco, pedagoga, especialista em Direito Educacional pelo Instituto Nacional de Educação e Qualificação Profissional e especialista em Educação Financeira pela Escola Superior de Administração - HSM. 


\begin{abstract}
The education, according to TRINDADE (2007), is vital to break with our country's historic scientific, technological and cultural dependence and to consolidate a democratic, autonomous, sovereign and supportive nation project. Thus fostering a growth of the social body towards a Democratic State of Right that makes effective the fulfillment of Fundamental and Social Rights. The right to education, as a subjective public right, is a fundamental social right. The articles 6 and 205 of the Federal Constitution, with three defined objectives, are directly related to the foundations of the Brazilian State: a) full development of the person; b) preparation for the exercise of citizenship; and c) qualification for work. The general objective of this study was to verify the right to early childhood education in São Paulo - SP and to analyze the number of places, the demand and the process of judicialization. In this sense, through the report data of the General Ombudsman's Office and the Public Defender's Office of the State of São Paulo, we sought to understand how they organize and act in the face of possible violations of rights to early childhood education in the city of São Paulo. By the Municipal Executive Power, education is a priority since it is included in the management goals to be achieved, however, the incursions of the Public Prosecutor's Office with support in actions of the Public Defender's Office demonstrate the configuration of a proper goal, under the perspective of their respective institutions. Thus, this meeting of diverse interests often resorts to the General Ombudsman of the Municipality for a balance, or as a public space that mitigates conflicts including of a broad nature such as the public policy of early childhood education. The specific objective of the present work is to demonstrate the decisive contribution of the General Ombudsman in the discussions of public policies. The information on the processes related to childhood and youth are usually classified as a secret of justice, which prevents further research on the subject. Thus, it is relevant to discuss access to this type of information by society or, at least, the Academy, by means of a commitment to use this data for scientific research purposes.
\end{abstract}

Keywords: Child education. Vacancies. Judicialization. 


\section{INTRODUÇÃO}

A assistência judiciária dirigida aos necessitados em São Paulo foi realizada pela Defensoria Pública do Estado de São Paulo (SOARES, 2011, p. 214).

De acordo com Soares, no "início do funcionamento da Defensoria Pública em 2006, havia 351 procuradores do Estado atuando, distribuídos em apenas 21 das mais de 300 comarcas do Estado" (2011, p. 215).

A partir da instalação da Defensoria Pública no Estado de São Paulo em 2006, a área da infância e juventude foi definida como prioridade.

Em 2008, a Defensoria propôs ação civil pública para manter as creches e pré-escolas abertas no tempo de férias escolares sob o argumento de que as mães não teriam onde deixar os filhos no período de recesso escolar, o que comprometeria o sustento familiar. A Apelação $n^{\circ} 0221522-$ 90.2009.8.26.0000, julgada pela Câmara Especial do Tribunal de Justiça de São Paulo, manteve a decisão da Vara da Infância e Juventude de São Miguel Paulista, a qual determinou o funcionamento dos estabelecimentos de ensino da rede municipal durante as férias escolares.

Napolitano e Peixoto afirmam em artigo que, em torno do ano de 2008, quando as primeiras demandas de vagas em creche chegaram na DPE/SP, foram expedidos ofícios às diretorias municipais de ensino da região com o objetivo de proteger o direito à educação infantil (NAPOLITANO; PEIXOTO, [s.d.]).

Sustentam ainda que, a partir do retorno dos ofícios contendo a afirmação da ordem do cadastro das crianças para a organização de interessados e eventual surgimento de vagas para posterior matrícula, a DPE/SP prosseguiu com a exigência impetrando mandados de segurança (NAPOLITANO; PEIXOTO, [s.d.]).

Os Defensores Públicos apresentaram como causa do aumento um "efeito boca-boca", sendo: (1) do momento em que uma pessoa procura um estabelecimento de ensino ou outra instituição da rede municipal de educação e recebe a informação da existência de lista de espera da Secretaria Municipal de Educação (SME) e que os primeiros ocupantes dessa ordem geralmente são em razão de decisão judicial, ou ainda nos casos em que conhecem pessoas que realizaram a matrícula da criança com maior agilidade a partir de uma ação judicial; (2) da divulgação da Defensoria Pública nos meios de comunicação.

\section{DESENVOLVIMENTO}

\subsection{O Ordenamento Jurídico Brasileiro e o Direito à Educação Infantil}

Com a promulgação da Constituição de 1988, a educação foi inscrita como um direito social e subjetivo, com garantia de acesso e qualidade, que compete à família, ao Estado e à sociedade. $\mathrm{O}$ texto também estabeleceu o direito da criança de 0 a 6 anos a creche e pré-escola e responsabilizou a União pela elaboração das diretrizes e bases da educação. Essa ação culminou na nova Lei de Diretrizes e Bases da Educação em 1996, Lei nº 9.394/96. 


\subsection{A Educação na Constituição de 1988}

A Constituição de 1988 é a mais extensa de todas em matéria de educação, sendo detalhada em dez artigos específicos (arts. 205 a 214) e figurando em cinco outros dispositivos (arts. 22, XXIV, 23, V, 30, VI, da Constituição, e arts. 60 e 61 do Ato das Disposições Constitucionais Transitórias - ADCT). A Carta trata da educação em seus diferentes níveis e modalidades, abordando os mais diversos conteúdos.

Em sintonia com o momento de abertura política, o espírito do texto é o de uma "Constituição Cidadã" que propõe a incorporação de sujeitos historicamente excluídos do direito à educação, expressa no princípio da "igualdade de condições para o acesso e permanência na escola" (art. 206, I). Outras conquistas asseguradas são: a educação como direito público subjetivo (art. 208, § $1^{\circ}$ ), o princípio da gestão democrática do ensino público (art. 206, VI), o dever do Estado em prover creche e pré-escola às crianças de 0 a 6 anos de idade (art. 208, IV), a oferta de ensino noturno regular (art. 208, VI), o ensino fundamental obrigatório e gratuito, inclusive aos que a ele não tiveram acesso em idade própria (art. 208, I), o atendimento educacional especializado aos portadores de deficiências (art. 208, I).

Os princípios norteadores do ensino são tratados em um mesmo artigo (art. 206). Além daqueles já mencionados antes (art. 206, I e VI), outros cinco assim se expressam: a "liberdade de aprender, ensinar, pesquisar e divulgar o pensamento, a arte e o saber"; o "pluralismo de ideias e de concepções pedagógicas, e coexistência de instituições públicas e privadas de ensino"; a "gratuidade do ensino público em estabelecimentos oficiais"; a "valorização dos profissionais do ensino, garantido, na forma da lei, plano de carreira para o magistério público, com piso salarial profissional e ingresso exclusivamente por concurso público de provas e títulos, assegurado regime jurídico único para todas as instituições mantidas pela União"; e a "garantia de padrão de qualidade" (art. 206, I, II, IV, V e VI) (VIEIRA, 2007).

A Constituição de 1988 mantém a competência privativa da União para "legislar sobre diretrizes e bases da educação nacional" (art. 22, XXIV), compartilhada com os Estados, o Distrito Federal e os Municípios para "proporcionar os meios de acesso à cultura, à educação e à ciência" (art. 23, V). Aos municípios é atribuída a manutenção, "com a cooperação técnica e financeira da União e do Estado, os programas de educação pré-escolar e de ensino fundamental" (art. 30, VI) e a orientação reforçada na determinação de sua atuação prioritária no ensino fundamental e pré-escolar (art. 211, § $2^{\circ}$ ).

A articulação entre as esferas do Poder Público é expressa na afirmação de que "a União, os Estados, o Distrito Federal e os Municípios organizarão em regime de colaboração seus sistemas de ensino" (art. 211). Nessa perspectiva, cabe à União organizar e financiar "o sistema federal de ensino e o dos Territórios" e prestar "assistência técnica e financeira aos Estados, ao Distrito Federal e aos Municípios para o desenvolvimento de seus sistemas de ensino e o atendimento prioritário à escolaridade obrigatória" (art. 211, $\S 1^{\circ}$ ).

A vinculação de recursos para a educação recebeu tratamento prioritário, sendo estabelecido que a União aplicaria "anualmente, nunca menos de dezoito, e os Estados, o Distrito Federal e os Municípios vinte e cinco por cento, no mínimo, da receita resultante de impostos, compreendida a 
proveniente de transferências, na manutenção e desenvolvimento do ensino" (art. 212). O mesmo artigo assegura como prioritário na distribuição de recursos públicos o "atendimento das necessidades do ensino obrigatório, nos termos do plano nacional de educação" (art. 212, § $3^{\circ}$ ). Mantém-se como fonte adicional de financiamento a este nível de ensino público "a contribuição social do salário-educação, recolhida, na forma da lei, pelas empresas, que dela poderão deduzir a aplicação realizada no ensino fundamental de seus empregados e dependentes" (art. $212, \S 5^{\circ}$ ). Ainda sobre a matéria cabe assinalar que o financiamento dos "programas suplementares de alimentação e assistência à saúde" seria advindo de "recursos provenientes de contribuições sociais e outros recursos orçamentários" (art. 212, § $4^{\circ}$ ).

Concluindo o mapeamento das questões relativas à educação na Carta de 1988, cabe ainda mencionar a previsão de lei para estabelecer o Plano Nacional de Educação (art. 214), assim como a concentração de esforços do Poder Público na eliminação do analfabetismo e na universalização do ensino fundamental (ADCT, art. 60) (VIEIRA, 2007).

\subsection{A Lei de Diretrizes e Bases da Educação Nacional - Lei n 9394/1996}

A Lei de Diretrizes e Bases da Educação Nacional - LDBEN foi sancionada pelo presidente Fernando Henrique Cardoso e pelo ministro da Educação Paulo Renato em 20 de dezembro de 1996. Baseada no princípio do direito universal à educação para todos, a LDB de 1996 trouxe diversas mudanças em relação às leis anteriores, como a inclusão da educação infantil (creches e pré-escolas) como primeira etapa da educação básica.

As principais características tiveram Darcy Ribeiro como relator; gestão democrática do ensino público e progressiva autonomia pedagógica e administrativa das unidades escolares (art. 3 e 15); ensino fundamental obrigatório e gratuito (art. 4); carga horária mínima de oitocentas horas distribuídas em duzentos dias na educação básica (art. 24); prevê um núcleo comum para o currículo do ensino fundamental e médio e uma parte diversificada em função das peculiaridades locais (art. 26); Formação de docentes para atuar na educação básica em curso de nível superior, sendo aceita para a educação infantil e as quatro primeiras séries do fundamental formação em curso Normal do ensino médio (art. 62); formação dos especialistas da educação em curso superior de pedagogia ou pós-graduação (art. 64); a União deve gastar no mínimo 18\% e os estados e municípios no mínimo $25 \%$ de seus respectivos orçamentos na manutenção e desenvolvimento do ensino público (art. 69); dinheiro público pode financiar escolas comunitárias, confessionais e filantrópicas (art. 77) e prevê a criação do Plano Nacional de Educação (art. 87).

O texto aprovado em 1996 é resultado de um longo embate, que durou cerca de seis anos, entre duas propostas distintas. A primeira conhecida como Projeto Jorge Hage foi o resultado de uma série de debates abertos com a sociedade, organizados pelo Fórum Nacional em Defesa da Escola Pública, sendo apresentada na Câmara dos Deputados. A segunda proposta foi elaborada pelos senadores Darcy Ribeiro, Marco Maciel e Maurício Correa em articulação com o poder executivo através do Ministério da Educação.

A principal divergência era em relação ao papel do Estado na educação. Enquanto a proposta 
dos setores organizados da sociedade civil apresentava uma grande preocupação com mecanismos de controle social do sistema de ensino, a proposta dos senadores previa uma estrutura de poder mais centrada nas mãos do governo. Apesar de conter alguns elementos levantados pelo primeiro grupo, o texto final da LDB se aproxima mais das ideias levantadas pelo segundo grupo, que contou com forte apoio do governo de Fernando Henrique Cardoso nos últimos anos da tramitação, com a estrutura composta por 92 artigos.

\subsection{O Estatuto da Criança e do Adolescente - Lei $n^{\circ}$ 8069/1990}

O Estatuto da Criança e do Adolescente - ECA, é um conjunto de normas do ordenamento jurídico brasileiro que tem como objetivo a proteção integral da criança e do adolescente, aplicando medidas e expedindo encaminhamentos para o juiz. É o marco legal e regulatório dos direitos humanos de crianças e adolescentes.

O ECA foi instituído pela Lei 8.069 no dia 13 de julho de 1990. Regulamenta os direitos das crianças e dos adolescentes inspirada pelas diretrizes fornecidas pela Constituição Federal de 1988, internalizando uma série de normativas internacionais, como Declaração dos Direitos da Criança; Regras Mínimas das Nações Unidas para Administração da Justiça da Infância e da Juventude (Regras de Beijing) e Diretrizes das Nações Unidas para prevenção da Delinquência Juvenil.

O Estatuto divide-se em dois livros: o primeiro trata da proteção dos direitos fundamentais à pessoa em desenvolvimento e o segundo trata dos órgãos e procedimentos protetivos. Encontram-se neles os procedimentos de adoção (Livro I, capítulo V), a aplicação de medidas socioeducativas (Livro II, capítulo II), do Conselho Tutelar (Livro II, capítulo V), e também dos crimes cometidos contra crianças e adolescentes.

É considerada criança a pessoa com idade inferior a doze anos e adolescente aquela entre doze e dezoito anos de idade. Para a prática de todos os atos da vida civil, como a assinatura de contratos, é considerado capaz o adolescente emancipado.

$\mathrm{O}$ adolescente pode ser apreendido em flagrante em um roubo ou em outros atos infracionais, assim como pode ser responsável pelos seus próprios atos.

As medidas socioeducativas são medidas aplicáveis a adolescentes autores de atos infracionais e estão previstas no art. 112 do Estatuto da Criança e do Adolescente (ECA). Destinam-se a pessoas na faixa etária entre 12 e 18 anos, podendo-se, excepcionalmente, estender sua aplicação a jovens com até 21 anos incompletos, conforme previsto no art. $2^{\circ}$ do ECA.

Apesar de configurarem resposta à prática de um delito, elas apresentam um caráter predominantemente educativo.

O juiz da Infância e da Juventude é competente para proferir sentenças socioeducativas, após análise da capacidade do adolescente de cumprir a medida, das circunstâncias do fato e da gravidade da infração. 


\section{A TRANSIÇÃO DA SECRETARIA MUNICIPAL DE ASSISTÊNCIA SOCIAL PARA SECRETARIA MUNICIPAL DE EDUCAÇÃO}

No início do século XX começava a industrialização no País, e as cidades das regiões mais ricas tornavam-se atrativas aos migrantes de outras regiões, que vinham em busca de uma melhor qualidade de vida.

Os segmentos da sociedade civil que se mobilizavam para apoiar a assistência às crianças necessitadas acreditavam que as creches eram necessárias por serem uma forma de conter a marginalidade e a criminalidade decorrentes da desorganização das famílias. Eram também necessárias devido ao ingresso das mulheres no mercado de trabalho. Acreditavam, inclusive, que poderiam contribuir para reduzir os altos índices de mortalidade infantil.

Segundo FRANCO (2009), na Prefeitura Municipal de São Paulo esse movimento de transição imposto pela Lei ocorreu morosamente, sendo esse aspecto outro elemento de pesquisa pelo presente trabalho.

As creches, entendidas como equipamentos que atendem crianças de zero a seis anos de idade em São Paulo - SP, tiveram início na década de 1950, sempre ligadas aos órgãos de Assistência Social, mantendo seu caráter assistencial, ou seja, atendimento aos filhos de mães trabalhadoras e crianças em situação de risco social ou moral.

Através do Decreto 40.268/01 vêm orientações para o atendimento em creche, contendo as diretrizes de integração e determinando as competências da Secretaria de Assistência Social (SAS) e da Secretaria Municipal de Educação (SME), visando o trabalho conjunto de atendimento a crianças de zero a seis anos e onze meses em creche.

A configuração passou, então, a contar com 31 Subprefeituras com 31 Coordenadorias de Saúde, 31 de Educação, 31 de Ação Social e assim sucessivamente, com todas as áreas sendo coordenadas nas regiões por subprefeitos, mas também respondendo às suas respectivas secretarias. Não houve só a descentralização do Orçamento Municipal, também se transferiram as decisões dos secretários para os subprefeitos, planejando-se a intersetorialidade e a integração das ações políticas efetuadas pelas coordenadorias das diversas áreas (Educação, Planejamento, Saúde, Ação Social, Obras, Finanças etc.).

Dentro dessa nova perspectiva, houve um rearranjo desses órgãos representantes das Secretarias Municipais nas regiões da cidade, o que melhorou a organização no atendimento à população na medida em que as divisões administrativas dos diferentes setores públicos foram reagrupadas por territorialidade.

\section{A JUDICIALIZAÇÃO DO DIREITO À EDUCAÇÃO INFANTIL EM SÃO PAULO - SP}

O acesso à justiça é direito humano fundamental segundo a Constituição Federal de 1988. Esse conceito abrange não apenas o direito de ingresso às instâncias do Poder Judiciário, mas também uma multiplicidade de direitos, os quais perpassam pelo reconhecimento e aplicabilidade de direitos regidos pela $\mathrm{CF} / 1988$. 
No entanto, Cappelletti e Garth observaram os obstáculos que o aspecto econômico gera com custos decorrentes de preparos, custas judiciais, peritos, honorários advocatícios e descolamento das partes agravadas pela morosidade dos processos (CAPPELLETTI; GARTH, 1988).

O tema do acesso à justiça no Brasil, a partir da redemocratização, transparece, entre diversos aspectos, na criação dos Juizados de Pequenas Causas (Lei n 7.244/1984), posteriormente com os Juizados Especiais Cíveis e Criminais (Lei n 9.099/1995), na ampliação das atribuições do Ministério Público e com o advento da garantia da assistência jurídica integral aos necessitados como missão institucional da Defensoria Pública, na Constituição Federal de 1988.

Concomitante ao conceito de que o acesso ao Poder Judiciário pode ser sinônimo de acesso à justiça, em sentido amplo, a redemocratização marca a retomada do espaço público que dá voz ao cidadão: as Ouvidorias Públicas. Em 1986 foi emblemática e constitui um marco referencial, a criação da Ouvidoria Municipal de Curitiba, que, entre outros temas, também se ocupou do acesso aos serviços básicos aos cidadãos.

\section{A ATUAÇÃO DAS INSTITUIÇÕES}

\subsection{O Ministério Público}

O Ministério Público é uma instituição prevista na Constituição de 1988 e regida pelos princípios da unidade, da indivisibilidade e da independência funcional. Entre suas funções, deve zelar pelo respeito dos Poderes Públicos e dos serviços de relevância pública, além de promover inquérito civil e ação civil pública para a proteção de interesses difusos e coletivos (CORRÊA, 2014, p. 85).

Na Lei da Ação Civil Pública (Lei no 7.347/85) também foi prevista a legitimidade do Ministério Público para propositura desse tipo de ação, bem como sua participação como fiscal da lei naquelas em que não for parte.

O Ministério Público passa a propor ações no Judiciário com o objetivo de efetivar o direito à educação infantil por meio de vagas em creches. Desde então, fazia acordos para a expansão numérica das vagas. Em consequência disso, procurava se especializar na área da educação, a partir do contato com especialistas no tema, para compreender também os parâmetros de qualidade.

\subsubsection{A Ouvidoria-Geral do Município de São Paulo}

Considerando que a Ouvidoria Pública é um espaço de escuta qualificada do cidadão, potencializando sua voz como caixa de ressonância na Administração Pública, é por consequência o registro de manifestações referentes à prestação de serviços disponibilizados pela Secretaria Municipal da Educação, especialmente sobre a falta de vagas, denúncia de eventual favoritismo, erros cadastrais, descumprimento da ordem sequencial de acesso às vagas, entre outros fatores relacionados diretamente às vagas em escolas e creches.

O registro de atendimento da Ouvidoria-Geral do Município de São Paulo indica um recorte de 
uma problemática do universo em que estiver inserido. Dito de outra forma, ele é representativo enquanto conteúdo de um cenário maior, ainda que não apresente expressão em números absolutos. Essa constatação, embora o sistema operacional não permitisse esse refinamento estatístico, decorre da familiaridade do registro e processamento das manifestações, pois entre eles há relatos de que recorrer à Ouvidoria-Geral foi uma recomendação da própria Defensoria Pública, que obteria documentação oficial para dar robustez ao pedido de vaga perante o Poder Judiciário.

Nesse passo, as organizações sociais que se dedicaram ao tema por vezes também recorreram ou recomendaram que se recorresse à Ouvidoria-Geral como forma de aferição do controle e participação social na discussão da política pública referente à educação infantil.

Para ilustrar a atuação das Organizações Sociais, destaque-se a entrevista com Ester Rizzi, advogada e assessora da Ação Educativa, que expressamente consigna que as "ações judiciais que pedem o reconhecimento do direito à educação infantil - e outros direitos educacionais - têm por objetivo fortalecer a percepção de que esses direitos são, efetivamente, direitos. Não basta estar garantido na Constituição, que é o primeiro passo, as instituições do Estado têm que ser pressionadas a agir de acordo com o que determina a legislação". E se, após ser condenado em sentença, o município continuar a violar o direito à educação infantil, porque a criança cresceu e não pode mais ser matriculada, a solução, levando o direito a sério, é a conversão da obrigação de fazer (matricular) em indenização (RIZZI, 2018).

\subsubsection{A Defensoria Pública do Estado de São Paulo}

A Defensoria Pública tem previsão no artigo 134 da Constituição Federal, com a função de orientação jurídica, promoção dos direitos humanos e defesa, em todos os graus, judicial e extrajudicial, dos direitos individuais e coletivos, de forma integral e gratuita aos necessitados. A Defensoria Pública do Estado de São Paulo foi criada no ano de 2006, mas, segundo relato do defensor doutor Luiz Raskovski, passou a atuar mais fortemente em educação no ano de 2010.

A Defensoria possui um núcleo de proteção às crianças e aos adolescentes que está muito ligado à área da educação. Além disso, possui a assessoria civil, que se dedica também de forma ativa a essa questão da educação.

Por conta disto, a Defensoria possui um procedimento específico para atendimento desses pais, ou seja, se os pais já estiverem de posse de toda a documentação, são atendidos na hora e é preenchido um modelo de ação judicial que será imediatamente encaminhada ao Judiciário, em consequência enviada ao Município, que por sua vez a passa para a Secretaria Municipal de Educação; muitas vezes todo esse ciclo inicia-se com o atendimento presencial, via e-mail ou telefone, pela Ouvidoria-Geral do Município.

A Ouvidoria-Geral do Município de São Paulo, no ano de 2016, realizou o total de 390 (trezentos e noventa) atendimentos via ofício ao órgão Secretaria Municipal de Educação, em 2017 foram 180 (cento e oitenta), já em 2018 disparou para 547 (quinhentos e quarenta e sete) atendimentos, com resposta via e-mail ou presencial aos munícipes (dados da publicação dos Relatórios Anuais da Controladoria-Geral do Município de São Paulo). 
São demandas do município que conta com cerca de 12.176.866 habitantes (dados do IBGE de 2018), com tendência de crescimento, visto dados da economia nacional e a convalidação da sociedade paulistana pelo órgão de Ouvidoria Municipal.

\section{CONSIDERAÇÃO FINAIS}

O Poder Judiciário tem constantemente sentenciado o município de São Paulo ao dever obrigacional de conceder vagas em instituições de educação infantil, seja ela creche ou pré-escola. O Tribunal de Justiça de São Paulo tende a manter essas decisões, inclusive tendo editado súmulas, como as 63 e 65 a respeito da vaga em creches.

Súmula 63: É indeclinável a obrigação do município de providenciar imediata vaga em unidade educacional à criança ou adolescente que reside em seu território.

Súmula 65: Não violam os princípios constitucionais da separação e independência dos poderes, da isonomia, da discricionariedade administrativa e da anualidade orçamentária as decisões judiciais que determinam às pessoas jurídicas da administração direta a disponibilização de vagas em unidades educacionais ou o fornecimento de medicamentos, insumos, suplementos e transportes a crianças ou adolescentes.

Assim, os números da judicialização atomizada são bastante expressivos nesse sentido.

A Procuradoria do Município de São Paulo alega genericamente o cumprimento das obrigações legais na medida do possível, considerando o orçamento do Município e que a decisão condenatória adentraria a discricionariedade do Poder Executivo em decidir sobre políticas públicas. Para o Município reverter esse quadro, é possível a argumentação estar pautada em dados de custos da política pública, cumprimento de metas, demonstração de política de ampliar o número de vagas, um mapeamento das possibilidades e prazos.

O Judiciário se sente confortável em condenar o Município à concessão de vagas, desde que o pedido seja individualizado. Desconsidera o Plano de Metas, inclusive no exercício de 2019, da correspondência do orçamento em relação ao objetivo estratégico².

Percebeu-se que essas decisões, apesar de não terem consequências diretas no planejamento da política, geram desigualdades com as demais crianças da fila de espera, já que sua única consequência é passar as crianças com decisão judicial à frente da fila. Além disso, as decisões judiciais também impedem que a Prefeitura adote uma lógica de priorização das crianças provenientes de famílias mais vulneráveis a partir do Cadastro Único.

As novas vagas são abertas todos os anos pela Prefeitura e preenchidas em grande medida por menores com sentença judicial em seu favor, desvirtuando a ordem da fila de espera e prejudicando aqueles que não têm acesso ao Poder Judiciário.

Nesse sentido, por meio dos dados de relatório da Ouvidoria-Geral do Município de São Paulo, buscou-se compreender como se organizam e atuam no enfrentamento a possíveis violações de direitos à educação infantil no Município.

2 Disponível em: <http://planejasampa.prefeitura.sp.gov.br/assets/up/Programa\%20Metas\%202019-2020_texto.pdf>. 
Pelo Poder Executivo Municipal, a educação é prioridade posto que consta nas metas de gestão a serem atingidas, contudo as incursões do Ministério Público com apoio em ações da Defensoria Pública demonstram a configuração de uma meta própria, sob ótica das suas respectivas instituições.

Dessa forma, nesse encontro de interesses diversos, a população mais vulnerável recorre à Ouvidoria-Geral do Município para um equilíbrio, ou como espaço público que mitiga conflitos, inclusive de natureza abrangente como a política pública da educação infantil, de forma decisiva e que acompanha do início da reclamação ou da denúncia à resposta final, tão esperada pela família, da vaga na creche ou no Centro de Educação Infantil da capital de São Paulo.

\section{REFERÊNCIAS}

ANDRADE, Cássio Cavalcante. Direito Educacional - Interpretação do Direito Constitucional à Educação. Belo Horizonte: Fórum, 2013.

BRASIL. Constituições Brasileiras: 1988. Senado Federal e Ministério da Ciência e Tecnologia, Centro de Estudos Estratégicos. Brasília, DF, v. VII, 2003.

Lei nº 9.394 de 20 de dezembro de 1996, Lei de Diretrizes e Bases da Educação Nacional. Brasília, 1996.

Lei 8.069 de 13 de julho de 1990, que trata do Estatuto da Criança e do Adolescente, com a nova redação dada pela Lei nº 10.764 de 12 de novembro de 2003. Brasília, 2003.

CAPPELLETTI, Mauro. Formações sociais e interesses coletivos diante da justiça civil. Revista de Processo, v. 5, p. 128-154, jan. 1977.

CORRÊA, Luiza Andrade. A judicialização da política pública de educação infantil no Tribunal de Justiça de São Paulo. 2014. Dissertação - Faculdade de Direito, Universidade de São Paulo, São Paulo.

CUNHA, Luciana Gross Siqueira. O acesso à justiça e assistência jurídica em São Paulo. 1999. Dissertação (Mestrado) - Departamento de Ciência Política da Faculdade de Filosofia, Letras e Ciências Humanas da Universidade de São Paulo, São Paulo.

FILGUEIRA, Yasmin Von Glehn Santos; GONÇALVES, Gabriella Vieira Oliveira; BRITO, Lany Cristina Silva (Org.). IV Diagnóstico da Defensoria Pública no Brasil. Brasília: Ministério da Justiça, Secretaria de Reforma do Judiciário, 2015. Disponível em: <https://www.anadep.org.br/wtksite/downloads/iv-diagnostico-da-defensoria-publica-no-brasil. pdf>. Acesso em: $1^{\circ}$ jun. 2018.

FRANCO, Dalva de Souza. Gestão de Creches para além da Assistência Social - Transição e percurso na Prefeitura de São Paulo 2001 a 2004. 2009. Dissertação - Faculdade de Educação, Universidade de São Paulo, São Paulo.

GARAVITO, César Rodríguez; FRANCO, Diana Rodríguez. Cortes y cambio social: cómo la Corte Constitucional transformó el desplazamiento forzado en Colombia. Bogotá: Centro de Estudios de Derecho, Justicia y Sociedad, Dejusticia, 2010.

IBGE - Instituto Brasileiro de Geografia e Estatística. Panorama da população do município de São Paulo - SP. Disponível em: <https://cidades.ibge.gov.br/brasil/sp/sao-paulo/panorama>. Acesso em: 25 jul. 2019.

MUNIZ, Cibele Cristina Baldassa. Dos direitos sociais e sua defesa pela Defensoria Pública. In: HADDAD, Eneida Gonçalves de Macedo. A Defensoria Pública do Estado de São Paulo: por um acesso democrático à Justiça. São Paulo: Letras Jurídicas, 2011. p. 251-295.

NAPOLITANO, Bruno Diaz; PEIXOTO, Leonardo Scofano Damasceno. O papel da defensoria pública na tutela coletiva de acesso à creche e pré-escola: um direito humano do núcleo familiar. Disponível em: <http://www.defensoria. sp.gov.br>. Acesso em: 11 maio 2018.

PIRES, Roberto Rocha C.; GOMIDE, Alexandre de Ávila. Capacidades estatais e democracia: arranjos institucionais de políticas públicas. Brasília: Ipea, 2014. 
PREFEITURA DE SÃO PAULO. Solicitação de Vagas. A solicitação de vagas para a Educação Infantil pode ser feita em qualquer época do ano para crianças de 0 zero a 5 (cinco) anos completos até 31 de março. Disponível em: <https://http://portal.sme.prefeitura.sp.gov.br/Main/Page/PortalSMESP/Solicitacao-de-Vagas>. Acesso em: 4 jun. 2018.

SADEK, Maria Tereza Aina. Estudos sobre o sistema de justiça. In: MICELI, Sérgio. O que ler na ciência social brasileira? São Paulo: Sumaré, v. IV, p. 126, 2002.

SILVA, Daniela Marques. Judicialização do Direito à Educação Infantil em São Paulo - SP. 2018. p. 106. Monografia - Faculdades Integradas Rio Branco, Faculdade de Direito, São Paulo. 